\title{
Inter-regional Input-output Analysis of the Three Provinces in Northeast China Based on the MRIO Model
}

\author{
Hai XIE ${ }^{1,}$ a , Fu GUO², Ping MEI ${ }^{2}$ \\ ${ }^{1}$ Harbin University, Harbin 150086, People's Republic of China \\ ${ }^{2}$ Harbin Institute of Technology, Harbin 150001, People's Republic of China \\ “axiehai68@163.com, bnoxygen@163.com, cwtonews@163.com.com
}

Keywords: MRIO model; Industrial correlation; Input-output; Northeast China

\begin{abstract}
The present paper analyzes the industrial correlation between the three provinces in Northeast China based on the MRIO model. The analysis result shows that industries in the three provinces in Northeast China increasingly tend to be identical; the traditional manufacturing industry is still the sector of high coefficients of influence while new types of service industry, such as the financial sector, computer service sector and software sector, feature comparatively low coefficients of influence. Meanwhile, the traditional manufacturing industry is more dependent on the economic activities of other industrial sectors. In contrast, some new types of the service industry will not be disturbed by the development of other industries. For this reason, positive measures should be taken primarily to expedite rationalization of the industrial structure; secondarily to reasonably guide the upgrading of the industrial structure; thirdly to persistently develop the competitive industries; finally to proactively cultivate the high and new technology industry. Efforts should also be made to support the industries in strong correlation with priorities in a bid to develop the endogenous power for regional economic growth and guarantee the sustainable and sound development of Northeast China's economy.
\end{abstract}

\section{Introduction}

The period since 2013 bore witness to the continuously slowed economic growth in the three provinces in Northeast China. It was described by the media to be "an emergency in Northeast China" and "precipitous fall of Northeast China's economy". From the 1950s, the worldwide developing countries began to speed up their industrialization process and the research on industrial correlation began to arouse the attention of the academic circles and the government. Based on the theory of uneven development, Hirschman (1958) proposed the concept of industrial correlation effect and pointed out that this effect could measure the relative degree of importance of the industries so as to work out the important industries driving fast economic growth [1]. In analyzing the industrial structure and assessing the industrial correlation effect, Chnery \& Watanable (1958) introduced the concepts of middle input rate and middle output rate and laid the foundation for the later input-output analysis [2]. Rasmussen (1956) brought forth the matrix of total demand coefficient (the Leontief inverse matrix) to analyze industrial correlation. His analytic approach exercised more far-reaching and more extensive influence on future research [3]. Yotopoulos \& Nugent (1973) thought Rasmussen's analytic approach based on the Leontief inverse matrix considered the direct and indirect relations between industries and the matrix of total demand coefficient can effectively overcome the problems of the incomplete measurement approach [4]. Augustinovics (1979) introduced the Ghosh model into industrial correlation analysis. That method brought the scholars to the awareness that the Ghosh model built from the perspective of product distribution could provide reasonable support of economic theories for industrial correlation analysis [5].

Isard (1951) was the earliest to propose the inter-regional input-output model. However, since this model requires dividing all the industries according to different areas, specific analysis requires that the quantity product flow in all areas in the region is known and the flow direction and quantity of flow of products in an area in the region are known. Nevertheless, these data are difficult to 
obtain. Therefore, the concrete application of the model is very difficult [6]. The research group of Polenske (1960), with the support of the Harvard economic research project, developed the inter-regional input-output model of 79 sectors in 51 areas in the United States by means of the MRIO model at the earliest [7]. The application of the MRIO model provides a quantitative economic method featuring low quantity demand for data, high result precision and comprehensive reflection of the inter-industrial input-output situation for us to research inter-regional industrial correlation.

The paper takes the three provinces in Northeast China as a whole and the inter-regional industrial correlation as the entry point to analyze the problems amid economic development of Northeast China. The MRIO model was introduced to build the inter-regional trade coefficient, focusing on calculating the inter-regional influence and the reaction degree. Based on analyzing the industrial structure of provinces and regions in Northeast China, the paper hopes to propose the regional development strategy of specific industries conform to the development status of Northeast China.

\section{The MRIO model}

The matrix of the MRIO model is:

$$
C=\left[\begin{array}{cccc}
C^{11} & C^{12} & \ldots & C^{m} \\
C^{21} & C^{22} & \ldots & C^{2 m} \\
\ldots & \ldots & \ldots & C \\
C^{m 1} & C^{m 2} & \ldots & C^{m m}
\end{array}\right], \quad C^{r s}=C A X+C F
$$

trade in sector i from area $\mathrm{r}$ to area $\mathrm{s}$;

$$
A=\left[\begin{array}{cccc}
A^{1} & 0 & \ldots & 0 \\
0 & A^{2} & \ldots & 0 \\
\ldots & \ldots & \ldots & \ldots \\
0 & 0 & \ldots & A^{m}
\end{array}\right] \text {, there into, } A^{r}=\left[\begin{array}{cccc}
a_{11}^{r} & a_{12}^{r} & \ldots & a_{1 n}^{r} \\
a_{21}^{r} & a_{22}^{r} & \ldots & a_{2 n}^{r} \\
\ldots & \ldots & \ldots & \ldots \\
a_{n 1}^{r} & a_{n 2}^{r} & \ldots & a_{n n}^{r}
\end{array}\right], a_{i j}^{r} \text { is the coefficient of direct }
$$

consumption from sector $\mathrm{i}$ to sector $\mathrm{j}$ in area $\mathrm{r}$;

$$
F=\left[\begin{array}{c}
F^{1} \\
F^{2} \\
\cdots \\
F^{m}
\end{array}\right], \quad X=\left[\begin{array}{c}
X^{1} \\
X^{2} \\
\cdots \\
X^{m}
\end{array}\right] \text {, respectively represent the end use and total output of all areas in the }
$$

region.

\section{Analysis of inter-regional industrial correlation in Northeast China}

The coefficients of industrial influence and reaction of Heilongjiang for Jilin and Liaoning are respectively shown in the following figures. They analyze the role of the industrial sectors of Heilongjiang in accelerating the industrial sectors of Jilin and Liaoning and the degree of influence of the economic and production activities of Jilin and Liaoning upon the output of the industrial sector of Heilongjiang. In Fig.1, the sector number is used to represent the industrial sector on the $\mathrm{x}$-coordinate.

Fig. 1 shows that the chart displays the astonishingly consistent trend of the coefficients of industrial influence of Heilongjiang upon Jilin and Liaoning. It mans that the influence of the industrial sector of Heilongjiang upon Jilin and Liaoning respectively is almost the same. Heilongjiang exerts greater influence on Jilin and Liaoning in agriculture, animal, husbandry and fishery, chemical industry, electric and thermal power production and supply industry, communication and transportation, warehousing industry, wholesale and retail sale trades but little influence in the rest industrial sectors especially the service industry. 


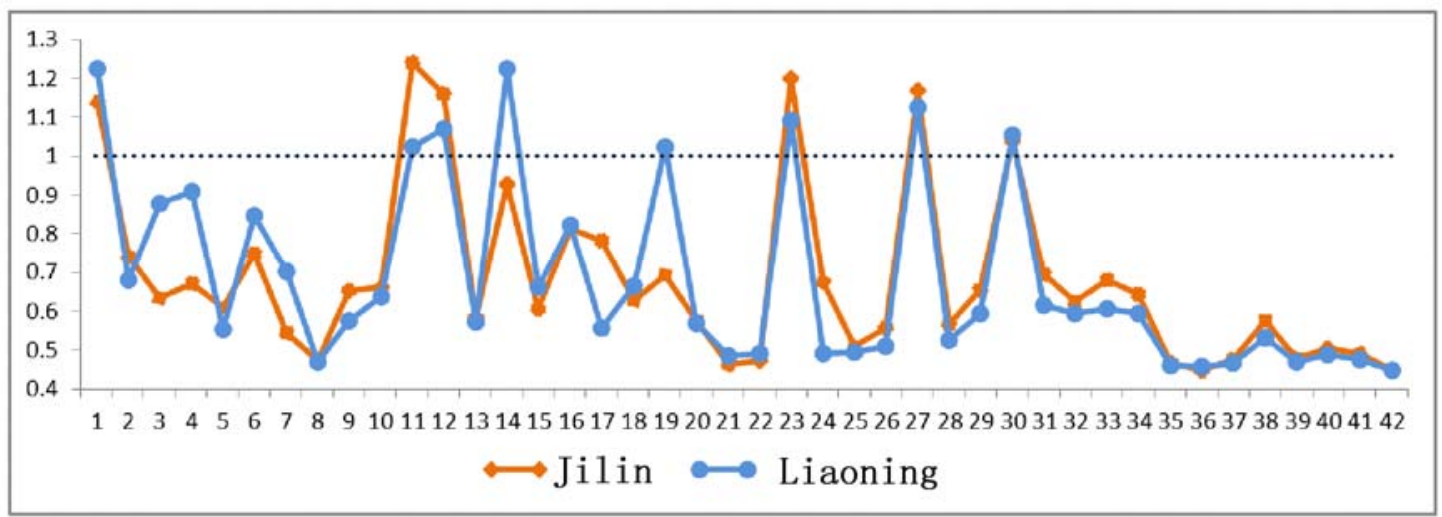

Fig. 1 Trend chart of the coefficients of industrial influence of Heilongjiang upon Jilin and Liaoning

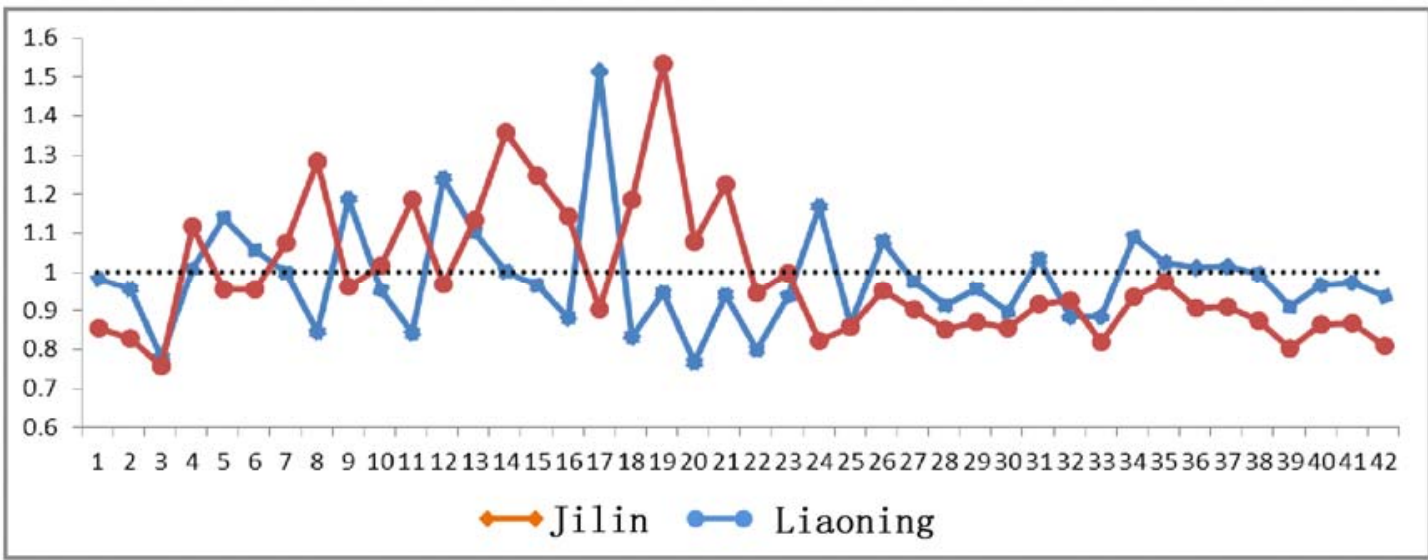

Fig. 2 Trend chart of the coefficients of industrial reaction of Heilongjiang to Jilin and Liaoning

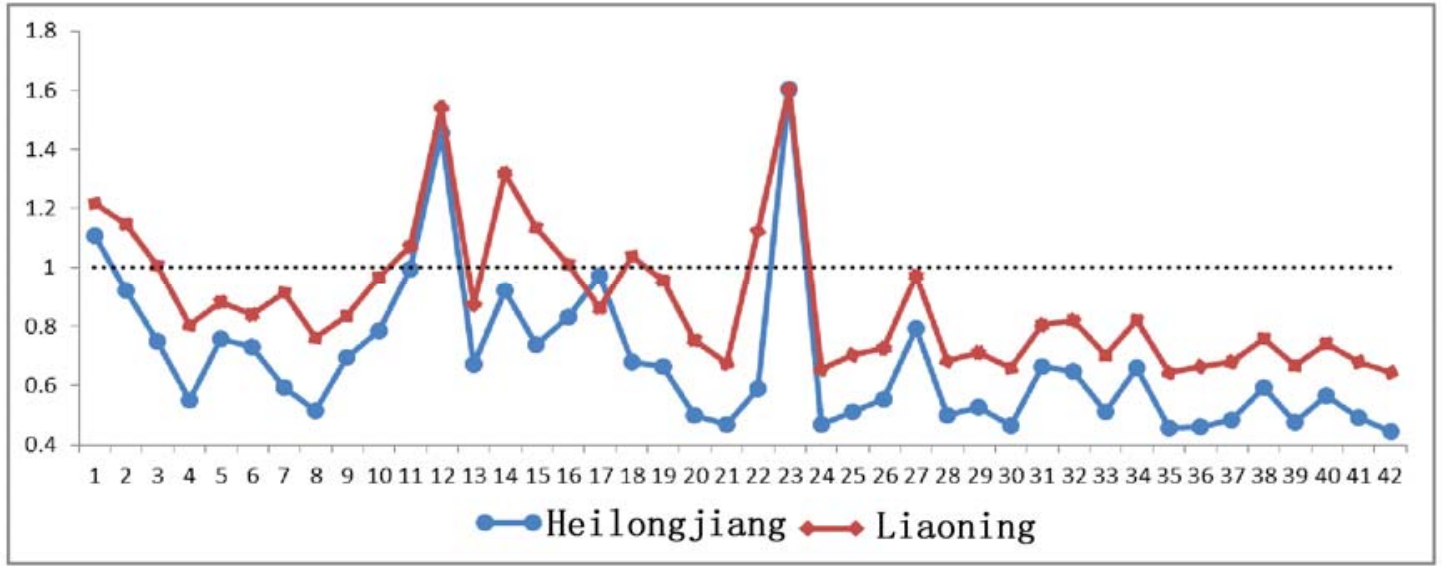

Fig. 3 Trend chart of the coefficients of industrial influence of Jilin on Heilongjiang and Liaoning

Fig. 2 indicates that the trend of the above coefficients of industrial reaction and coefficients of influence is inconsistent. It means that the economic and production activities in Jilin and Liaoning exert influence on the industrial sector of Heilongjiang to different extent. The coefficients of reaction to such industrial sectors as the nonmetal mineral products industry, timber processing and furniture manufacturing industry, transportation equipment manufacturing industry, chemical industry, gas production and supply, renting and commercial services of Jilin are rather comparatively higher. It exhibits that the economic and production activities of these industrial sectors in Heilongjiang highly depend on the economic activities in Jilin. However, the production activities of other industrial sectors are independent of Jilin. The coefficients of industrial reaction to metal mining and separating industry, clothing, leather, down feather and their product industry, oil processing, coking and nuclear fuel processing industry, coking and nuclear fuel processing industry, metal smelting and calendaring industry, communication device, computer and other 
electronic product manufacturing industry, and other manufacturing industries of Liaoning. It demonstrates that the economic activities of these sectors depend more on the economic growth of Liaoning compared with other sectors.

As shown in Fig.3, the influence of the industrial sector of Jilin upon Heilongjiang and Liaoning respectively is almost the same. The coefficients of influence of Jilin on Heilongjiang and Liaoning in agriculture, animal, husbandry and fishery, chemical industry, electric and thermal power production and supply industry are higher than the average. It indicates that the economic activities of these industrial sectors of Jilin exert a greater impact on accelerating those of Heilongjiang and Liaoning. Nevertheless, the coefficients of influence of other industries, especially the service industry, are lower than the average. The output of these industrial sectors has little influence on the economic activities of other provinces.

\section{Conclusions}

Regional development is a comprehensive issue relating to resources, administrative region planning, industrial layout, competition and cooperation. There are diverse factors influencing regional economic development. The paper starts from the angle of inter-regional industrial correlation and applies the MRIO model to analyze the industrial relationship between the three provinces in Northeast China. The analysis result shows, the industries of the three provinces tend to be identical; the traditional manufacturing industry is still the sector of high coefficients of influence while new types of service industry, such as the financial industry, computer services and software industry, have low coefficients of influence.

\section{Acknowledgements}

This work was financially supported by Heilongjiang Philosophy and Social Sciences Foundation (Grant No. 16JYD04).

\section{References}

[1] A. O. Hirschman. The Strategy of Economic Development. New Haven: Yale University Press. 1958

[2] H. B. Cheney. Watanabe T. International comparisons of the structure of production. Econometrica: Jo

[3] P. N. Rasmussen. Studies in inter-sectoral reation. Copenhagen/ Amsterdam. 1956

[4] P. A. Yotopoulos. Nugent J B. A balanced-growth version of the linkage hypothesis: a test. The Quart

[5] M. Augustinovics. Methods of international and intertemporal comparison of structure. Contributions

[6] W. Isard. Methods of regional analysis: an introduction to regional science. New York: The Technolog

[7] Polenske. The multiregional input-output (MRIO) model of the United States. MIT Press. 1980: 232-234 